\title{
An international perspective on the undercount of young children in the U.S. Census
}

\author{
William P. O'Hare \\ O'Hare Data and Demographic Services LLC, 11 Randolph Avenue, Cape Charles, VA 23310, USA \\ E-mail: billohare1@gmail.com
}

\begin{abstract}
The U.S. Census Bureau's Demographic Analysis shows that young children (age 0 to 4) had a higher net undercount rate than any other age group in the 2010 U.S. Decennial Census. Three key patterns are evident in the U.S. data relative to the net undercount of young children. First, there has been a relatively high net undercount of children under age 5 for several decades. Second, the net undercount for young children is higher than the net undercount for older children. Third, young children have a higher net undercount than any other age group. Data from several other countries are examined here to see if the patterns observed in the U.S. relative to the net undercount of young children are also seen in other countries. Examination of data from several countries indicates that most have experienced a net undercount of young children and that young children typically have higher net undercount rates than older children. However, in the countries where data were available, young children are not the age group with the highest net undercount. In most countries examined here young adults have a higher net undercount rate than young children.
\end{abstract}

Keywords: Census, undercount, children

\section{Introduction}

There is clear and strong statistical evidence that young children have been undercounted in the U.S. Decennial Census for several decades [19,30,34]. The U.S. Census Bureau's Task Force on the Undercount of Young Children in the Census [19, page i] concluded, "The undercount of children under age five in the decennial census, and in surveys like the American Community Survey (ACS) is real and growing."

This article examines the undercount pattern for young children in the U.S. Census relative to the results of censuses from several other countries. The analysis here is framed by comparing the results in other countries to the key results from the U.S. Census.

After a brief description of the Demographic Analysis methodology used to measure coverage in the 2010 U.S. Census, the key statistical data on the net undercount of young children in the 2010 U.S. Census are presented. There is also a brief review of the net undercount of young children historically in the U.S. Census. Then data from censuses of several other countries are examined in relation to the patterns seen in the U.S. Census. Three specific questions are addressed related to patterns seen in the U.S. Census:

1. Is it common to see a net census undercount rate (as opposed to a net overcount) for children under age 5 ?

2. Is the net undercount rate for children under age 5 typically higher than the net undercount rate for older children?

3 . Is the net undercount rate for children under age 5 typically higher than the net undercount rate for any other age group?

\section{Measuring net undercounts in the U.S. Census}

Several methods have been used over time and in various countries to determine who is missed in a census, but in the U.S. only the Demographic Analysis method and the Dual Systems Estimates method (sometimes called Post Enumeration Survey) provide quantitative results $[9,22,24]$. 
The analysis presented in the first part of this article rests largely on the results of the Census Bureau's Demographic Analysis (DA) method for assessing Census accuracy. Demographic Analysis or (DA) has been used since the 1950 s to provide estimates of net undercounts in the U.S. Census. This method creates a separate independent estimate of the expected population based largely on births and deaths which is compared to the Census counts to estimate census coverage.

DA is particularly well-suited for assessing the net undercount of young children in the U.S. because DA rests on highly accurate birth and death records and the least accurate component of DA, net international migration, is a very small component of DA population estimates for young children.

DA has been used for many decades, the underlying data and methodology are strong, and it has provided useful information for those trying to understand the strengths and weaknesses of the U.S. Decennial Census. According to Robinson [37, page 1] "The national DA estimates have become the accepted benchmark for tracking historical trends in net Census undercounts and for assessing coverage differences by age, sex, and race (Black, all other)."

It should be noted that the U.S. Census Bureau also uses a Dual-Systems Estimation approach based on a Post-Enumeration survey to assess census coverage. The net undercount estimate for children age 0 to 4 produced by the DA methodology is 4.6 percent compared to 0.7 percent produced by the DSE method. One set of researchers conclude that uncorrected correlation bias may explain why the DSE method underestimates the net undercount of young children [27]. The U.S. Census Bureau Task Force on the Undercount of Young Children also concluded that Demographic Analysis is the best method for assessing net undercounts of young children [19, page i].

Since there are already several detailed descriptions of the DA methodology available, I will only review the method briefly here $[20,38,48]$.

As described by the U.S. Census Bureau [51] the DA Population Estimates for age 0 to 74 are derived from the basic demographic accounting Eq. (1) applied to each birth cohort:

$$
P_{0-74}=B--D+\mathrm{NIM}
$$

$P_{0-74}=$ Population for each single year of age from 0 to 74 ;

$B=$ Number of births for each age cohort;

$D=$ Number of deaths for each age cohort since birth;
Table 1

Fundamental data for Census Bureau's DA estimate for the population age 0 to 4

\begin{tabular}{lr}
\hline Births (in five years prior to the 2010 Census) & $21,120,000$ \\
Deaths to those born in five years prior to Census & 154,000 \\
Net international migration & 240,000 \\
DA Population estimate for age 0 to 4 & $21,206,000$ \\
Population Age 0 to 4 counted in 2010 Census & $20,201,000$ \\
Source: U.S. Census Bureau, 2010b and 2012a & \\
\hline
\end{tabular}

$\mathrm{NIM}=$ Net International Migration for each age cohort.

For example, the estimate for the population age 17 on the April 1, 2010 Census date is based on births from April 1992 through March 1993, reduced by the deaths to that birth cohort in each year between 1992 and 2010, and incremented by Net International Migration (NIM) experienced by the cohort.

The U.S. Census Bureau's December 2010 DA "Middle Series" estimate for the population age 0 to 4 is comprised of 21,120,000 births, 154,000 deaths, and Net International Migration of 240,000 (see Table 1). Births are by far the largest component of the DA Population Estimates for young children. In 2010, births accounted for 99.6 percent of the DA population estimate for the population age 0 to 4 (see Table 1 ). Net International Migration for age 0 to 4 is estimated at 240,000 . Thus this component of the DA estimate is only 1.1 percent of the total.

Since Net International Migration accounts for such a small part of the DA estimate for the population age 0 to 4 , errors in this component of population change would not have a big impact on the final DA population estimate for the 0 to 4 age group. In addition, potential errors in the overall estimates of the DA estimates for the population age 0 to 4 are likely to be small, as discussed below.

The birth and death data used in the Census Bureau's DA estimates come from the U.S. National Center on Health Statistics (NCHS) and these records are widely viewed as being accurate and complete. The National Center for Health Statistics [25, page 2] states, "A chief advantage of birth certificate data is that information is collected for essentially every birth occurring in the country each year..." After a thorough review of vital statistics prior to the 2010 Census, the U.S. Census Bureau [16, page 5] stated:

_ "The following assumptions are made regarding the use of vital statistics for DA:

- Birth registration has been 100 percent complete since 1985. 
- Infant deaths were underregistered at one-half the rate of the underregistration of births up to and including 1959.

- The registration of deaths for ages 1 and over has been 100 percent complete for the entire DA time series starting in 1935."

The method used by the Census Bureau to calculate Net International Migration for the 2010 set of DA estimates for children under age 10 relies heavily on data from the Census Bureau's American Community Survey (ACS) where the location of the Residence One Year Ago (ROYA) is ascertained for everyone in the survey age 1 or older [8]. The total number of yearly immigrants is derived from this question in each year of the ACS, and then that total number of immigrants is distributed to demographic cells (sex, age and race) based on an accumulation of the same data over the last five years of the ACS. Five years of ACS data are used to provide more stable and reliable estimates for small demographic groups.

Statistics on emigration of the foreign-born population from the U.S. are based on a residual method comparing data on the foreign-born population from the 2000 Census to later ACS estimates to develop rates and then applying those rates to observed populations [13].

Emigration of U.S. citizens (net native migration) is derived by examining Census data from several other countries [39]. This method of estimating out migration is problematic for a couple of reasons. Data are not available for every country and the quality of some foreign Censuses is suspect. However, with few exceptions (see [36]) it is widely felt that emigration has little impact on DA Estimates for young children.

Initially the U.S. Census Bureau released their DA estimates for 2010 in early December of 2010 in an effort to publish the DA estimates before the 2010 Census results were released. This was done to try and mitigate perceptions that the DA results were influenced by the Census count which was not released until late December 2010 [52]. In May 2012, the Census Bureau issued revised Demographic Analysis estimates.

In preparing for the December 2010 DA release, the Census Bureau developed five estimation series with differing assumptions to reflect the degree of uncertainty in the DA estimates. For the population age 0 to 17 , the estimates from the five series presented in December 2010 range from 75,042,000 to 76,222,000 and for the population age 0 to 4 the estimates ranged from $21,181,000$ to $21,265,000$. This is a relatively small band of uncertainty compared to the estimated net undercount.

The assumptions about births and deaths were the same for each of the five series. Only the assumptions about Net International Migration varied. In those five series the Net International Migration assumptions for the population age 0 to 4 ranged from 214,000 to 297,000 [48]. The Middle Series estimate of net immigration for age 0 to 4 was 240,000 for the DA estimates released in December 2010. Thus the high end of the immigration assumption was 57,000 persons higher than the Middle Series and the low end was 26,000 persons lower than the Middle Series.

This provides some guidance about the size of potential errors in immigration estimates and population estimates used in DA for young children. If the Net International Migration component for children age 0 to 4 in the DA estimate from May 2012 had been 26,000 less, the net undercount of children age 0 to 4 in the 2010 Census would be 4.5 percent instead of the value of 4.6 percent reported in the May 2012 DA release. If the Net International Migration component for children age 0 to 4 had been 57,000 higher the net undercount estimates would have been 4.9 percent. In either case, the net undercount of young children would remain much higher than any other age group. If one wanted to look at an extreme case and assume there was no net immigration of children age 0 to 4 , the DA estimate for the net undercount of the population age 0 to 4 would be 3.6 percent, which is still much higher than for any other age group.

\subsection{Limitations of the demographic analysis method}

There are four major limitations to DA. First, it is only routinely available for the nation as a whole. The population age 0 to 9 is an exception to this rule. Subnational analysis can be done for the population under age ten, because the Census Bureau's Population Estimates for age 0 to 9 are not linked to the previous Census. State and county level undercount estimates for the population age 0 to 4 are provided by O'Hare [31,32].

Second, DA estimates are only available for a few race/ethnic groups. Historically the estimates have only been available for Black and Non-Black groups. This restriction is due to the lack of race specificity and consistency for data collected on the birth and death certificates historically. The only group that has been identified relatively consistently over time is Blacks (African-Americans).

The 2010 DA estimates include data for Hispanics for the first time, but only for the population under age 
20. Hispanics under age 20 were included in the DA estimates in 2010 because Hispanics have been consistently identified in birth and death certificates since 1990.

The $2010 \mathrm{DA}$ is the first to produce estimates of net undercount of Black Alone and Black Alone or in Combination. Recent changes in how the Census Bureau collects data on race raises questions about the comparability of the data for Blacks in the 2010 Census relative to earlier Censuses.

The third limitation of the DA estimates is that they only provide net undercount/overcount figures. A zero net undercount could be the result of no one being missed (omissions) or double counted (erroneous enumerations) or it could be the result of ten percent of the population being missed and ten percent double counted.

The fourth limitation of the DA methodology is the lack of any measures of uncertainty for the estimates similar to standard errors associated with surveys. However, as mentioned earlier, in the December 2010 DA release, the U.S. Census Bureau released five different estimate series based on five sets of assumptions about births, deaths, and Net International Migration to reflect some of the uncertainty regarding the DA estimates.

The Census counts and DA estimates are shown as the Census count minus the DA estimate. This is consistent with the convention used by Velkoff [59] in reporting the first results of the 2010 DA. This calculation is sometimes labeled "net Census coverage error" in other research. A negative number implies a net undercount and a positive number implies a net overcount. This may be a point of confusion because some studies have used a net undercount rate which subtracts the Census counts from the DA (or DSE) estimates. In that construction, a negative figure implies an overcount. I chose to use the net Census coverage error construction because I feel having an undercount reflected by a negative number is more intuitive. When figures are stated in the text as an undercount or an overcount, the positive and negative signs are not used.

In converting the differences between Census counts and DA estimates to percentages, the difference is divided by the DA estimate. Population Estimates are shown rounded to the nearest thousand for readability.

\section{Undercount of young children in the U.S. Census}

In this section, key results of research on the undercount of young children in the U.S. Census are pro- vided. Many details of the net undercount of young children in the U.S. Census are not addressed here in order to focus on the three key elements that will be examined in censuses from other countries. For those who wish to see a more detailed analysis of the net undercount of children in the U.S. Census see [28-30,32-34].

\subsection{0 demographic analysis results by age}

In the 2010 U.S. Census there was a net overcount of 0.1 percent of the total population based on DA, which translates into about 400,000 people [59]. However, the small net overcount for the total population masks important differences among some age groups.

Velkoff [59] shows the 0.1 percent net overcount for the entire population is a product of a 0.7 percent net overcount for adults (age 18 an older) and a 1.7 percent net undercount for children (age 0 to 17). In population numbers, these reflect a net undercount of 1.3 million children and a net overcount of 1.7 million adults. This underscores the extent to which the small difference between the 2010 U.S. Census and the DA estimates for the total population masks important differences by age.

Figure 1 shows the net undercount and overcount figures from the 2010 U.S. Census by five-year age groups for ages 0 to 85 plus. There is a large net overcount for young adults (roughly age 18 to 24) and a large net overcount for the population age 60 to 80 but there is a large net undercount for people under age 10 , particularly age 0 to 4 . Young children is the only age group with a significant net undercount.

As Fig. 1 suggests, there are big differences in net undercounts and overcounts for children based on their age. Figure 2 shows the net undercount rates for children by single year of age and underscores the extent to which net undercount rates for children vary by age. The highest net undercount rates are found among the youngest children, particularly age 0 to 4 . More than three-quarters of the 1.3 million person net undercount for the population age 0 to 17 can be accounted for by those age 0 to 4 , where the net undercount is about one million people.

There is a very clear age gradient along the age range from age 1 to 17 . The net undercount rate declines steadily from age 1 to age 13 and there is a net overcount in the 14 to 17 -year-old age group. The correlation coefficient between age and net undercount rate for the population age 0 to 17 is -0.96 . Recall that undercounts are a negative number so this correlation 


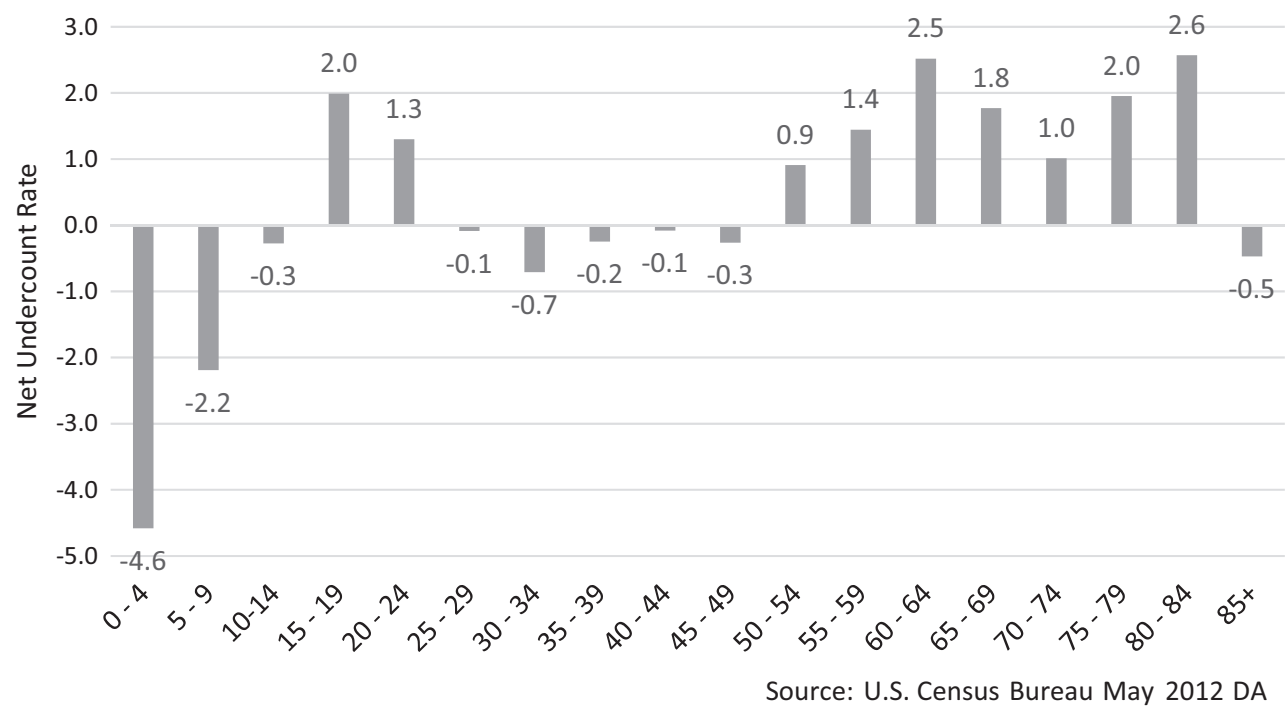

Fig. 1. Net undercount rate in 2010 U.S. Census by age.

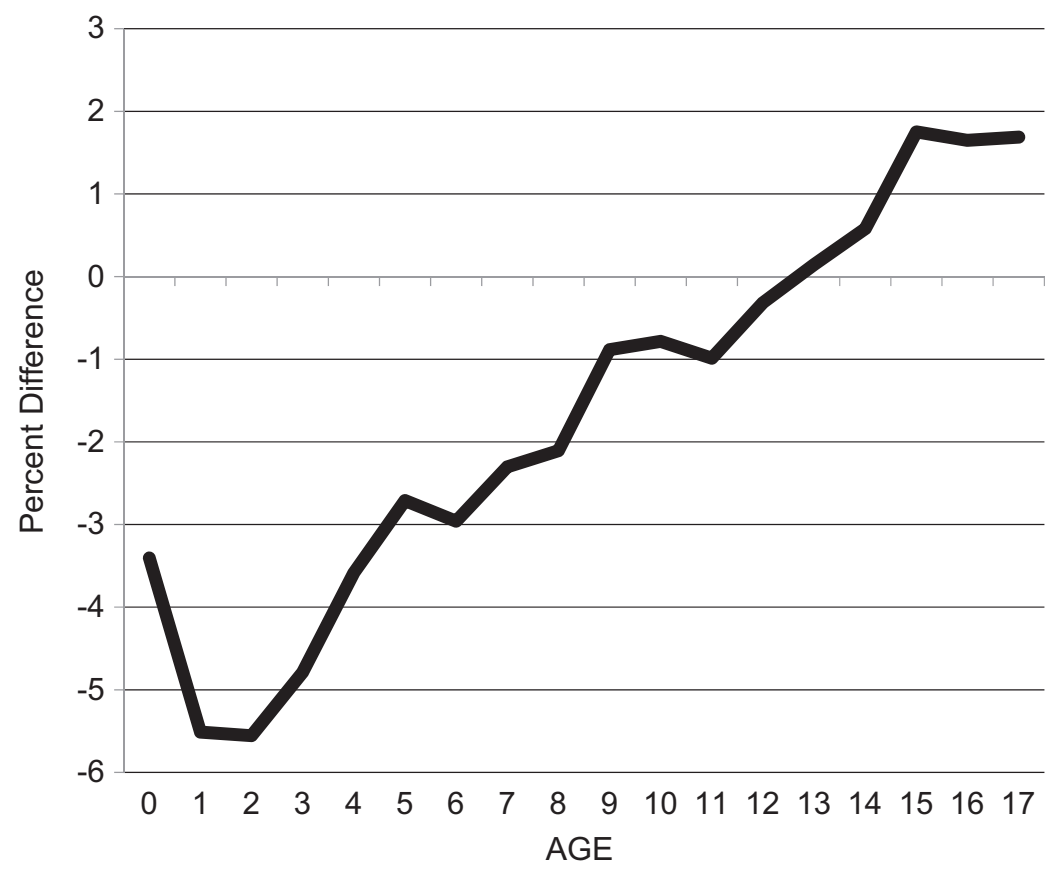

Source: U.S. Census Bureau May 2012 DA

Fig. 2. Percent difference between 2010 Census Counts and DA estimates by single year of age: 0-17.

means the higher the age the smaller the net undercount.

The relatively low net undercount for those age 0 (i.e. less than one year old) is noteworthy. It is also noteworthy that the net undercount rate for age 0 fell between the 2000 and the 2010 Censuses [34, Chapter 3]. In this context, it should be noted that some of the new instructions on the 2010 Census questionnaire were aimed specifically at making sure infants and newborns were included in the Census. Perhaps those instruction were responsible for the relatively low net undercount for age zero in the 2010 Census and the decline in the net undercount for age zero between the 2000 and 2010 Censuses. 
I am not aware of any published theories that attempt to explain the strong association between age and net undercount rates for children. If we had a better understanding of the reasons behind this age gradient, we might have a better understanding of why young children have such a high net undercount. This question deserves additional research attention.

The evidence above indicates the population age 0 to 17 should not be treated as a homogeneous group with respect to undercounts in the Census. Analysts who do not examine young children separately from older children will find it difficult to come up with an explanation for census coverage patterns.

Some researchers have suggested that "birth tourism" or "anchor babies" may play a role in the high net undercount of young children [36]. Neither one of these terms are very well defined, but both refer loosely to a practice of pregnant women from other countries coming to the U.S. to have the birth of their baby then leaving the country soon after the birth. This grants the baby U.S. citizenship.

Technically such births should not impact the assessment of coverage based on DA. Both the Census and the birth certificate systems assign a birth or a person to the usual place of resident [47]. So if a women came from another country to have a birth in the U.S. that birth would be assigned back to the usual place of residence. Moreover, while there are anecdotal evidence about this practice, I have been unable to find any systematic evidence.

It should also be noted that according to data on the website of the Migration Policy Institute, there were 76,000 undocumented immigrants under age 5 in the U.S. At least some of these young children would show up in the Census Count but not in the birth certificate data. To some extent this would balance any impact from anchor babies.

\section{Historical examination of net coverage error for children in the U.S. Decennial Census: 1950 to 2010}

The thrust of the analysis of U.S. Census coverage rates in this analysis is the results of the 2010 Census, but it is illuminating to look at the U.S. Census coverage rates of children over time.

The high net undercount rate for young children in the 2010 U.S. Census raises questions about the net undercount of children in U.S. Censuses historically. How do the net undercount rates for children in the
2010 U.S. Census compare to U.S. Census results in the past? Have children had a higher net undercount rate than adults in the past? Have younger children had a higher net undercount rate than older children in the past?

Despite data showing a high net undercount rate for children more than fifty years ago, I have been unable to find any reports or systematic examination of the trends over time in the net undercount of children in the U.S. Censuses. Looking at the trends from 1950 to 1980 it is understandable that the net undercount rates of young children were not singled out for attention because the net undercount of young children was not much different than the undercount for the total population, as shown later in this article. However, since 1980 it has been clear that the net undercount rates for young children have been very different than those of adults.

The time series examined here starts with the 1950 U.S. Census. DA estimates for the 1950 through 2000 U.S. Censuses are taken from a U.S. Census Bureau Working Paper [30]. The data in the working paper are derived from a U.S. Census Bureau internal file, which provides DA estimates of the population by age, sex, and race (Black and Non-Black) for each U.S. Census year. The corresponding counts from the U.S. Decennial Censuses are also available on this internal file.

These DA estimates are based on an on-going compilation of birth and death certificate data and Net International Migration estimates. Because the internal U.S. Census Bureau historical series has been updated regularly, the figures presented here may differ in very minor ways from data published previously by the U.S. Census Bureau.

Table 2 provides the data in tabular form but many of the key trends are better illustrated with graphs so key data from the tables are also presented in graphic form. The graphics provide a clearer picture of trends while the tables provide detailed statistical data that some readers may prefer.

\subsection{Historic patterns in the net undercount of adults and children}

Examination of net Census coverage rates from 1950 to 2010 indicates a significant and steady reduction in the net undercount for the total population. Figure 3 shows that the net undercount rate for the total population has fallen nearly every decade since 1950, reaching a small net overcount in 2010.

However, when the overall trend shown in Fig. 3 is decomposed by age, a somewhat different story 
Table 2

Net undercount rates in the U.S. Census for age groups: 1950 to 2010

\begin{tabular}{lrrrrrrr}
\hline & 1950 & 1960 & 1970 & 1980 & 1990 & 2000 & 2010 \\
\hline All ages & -3.7 & -2.5 & -2.4 & -0.9 & -1.6 & -0.1 & 0.1 \\
Aage 0 to 4 & -4.7 & -2.4 & -3.6 & -1.4 & -3.7 & -3.8 & -4.6 \\
Age 5 to 13 & -2.3 & -2.4 & -2.5 & -0.7 & -1.6 & -0.2 & -1.4 \\
Age 14 to 17 & -2.3 & -1.5 & 0.2 & 0.4 & -0.4 & 1.5 & 1.4 \\
Age 0 to 17 & -3.5 & -2.3 & -2.5 & -0.7 & -1.8 & -0.7 & -1.7 \\
Age 18 plus & -3.8 & -2.6 & -2.3 & -1 & -1.6 & 0.1 & 0.7 \\
Percentage Point Gap Between Adults and & 0.9 & -0.2 & 1.3 & 0.5 & 2.1 & 3.9 & 5.3 \\
Young Children (Adults - Young Children) & & & & & & & \\
Percentage Point Gap Between Adults and All & -0.3 & -0.3 & 0.2 & -0.3 & 0.2 & 0.7 & 2.4 \\
Children (Adults - All Children) & & & & & & & \\
Source: O'Hare 2014b & & & & & & &
\end{tabular}

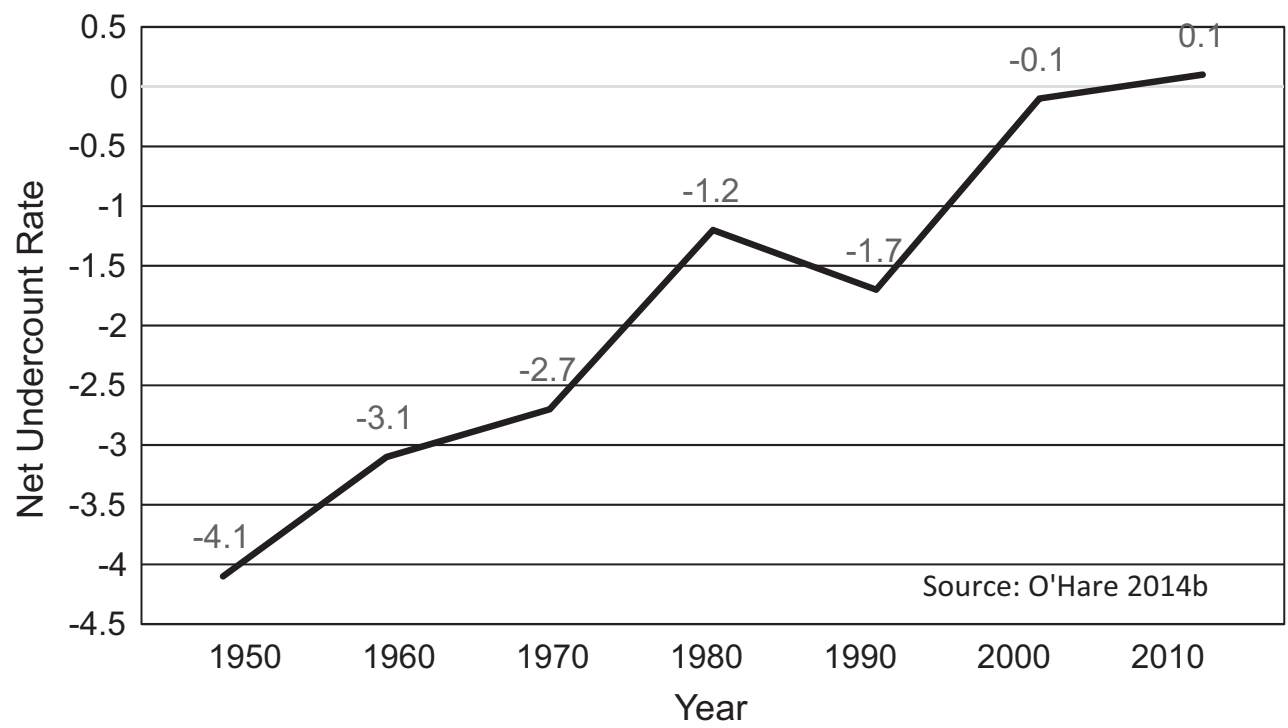

Fig. 3. Net undercount rates for total population 1950 to 2010

emerges. Figure 4 shows net undercount rates for the adult population (age 18 and older) and for three age groups of children (age 0 to 17) for each U.S. Census from 1950 to 2010. Figure 4 shows that there have been two very distinct periods between 1950 and 2010 in terms of the net undercount trends of adults and children. Between 1950 and 1980, the net undercount rates for both groups declined steadily and the differences between the net undercount rate of children and adults were not large.

Following the 1980 U.S. Census, the net undercount rates of young children and adults began to diverge. The coverage rates for adults continued the improvement seen in the 1950 to 1980 period while the net undercount rates for young children increased following 1980. Specifically, the coverage rates for adults went from 1.4 percent net undercount rate in 1980 to a 0.7 percent net overcount rate in 2010 . The net undercount rate for young children went from 1.4 percent in 1980 to 4.6 percent in 2010 .

The growing gap between net undercount rates for young children and adults since 1990 is due more to changes in the adult rates than in the rates for young children. The net undercount rates for adults have continued to improve while those for young children have not.

\subsection{Net undercount of children by age}

The overall trend in the net undercount rates of children from 1950 to 2010 reflects very different trajectories for children in different age groups. Figure 4 shows the trends in net Census undercount rates since 1950 for adults and three age groups of children; age 0 to 4 , age 5 to 13 , and age 14 to 17 . These age groupings were used because these groups have very different 


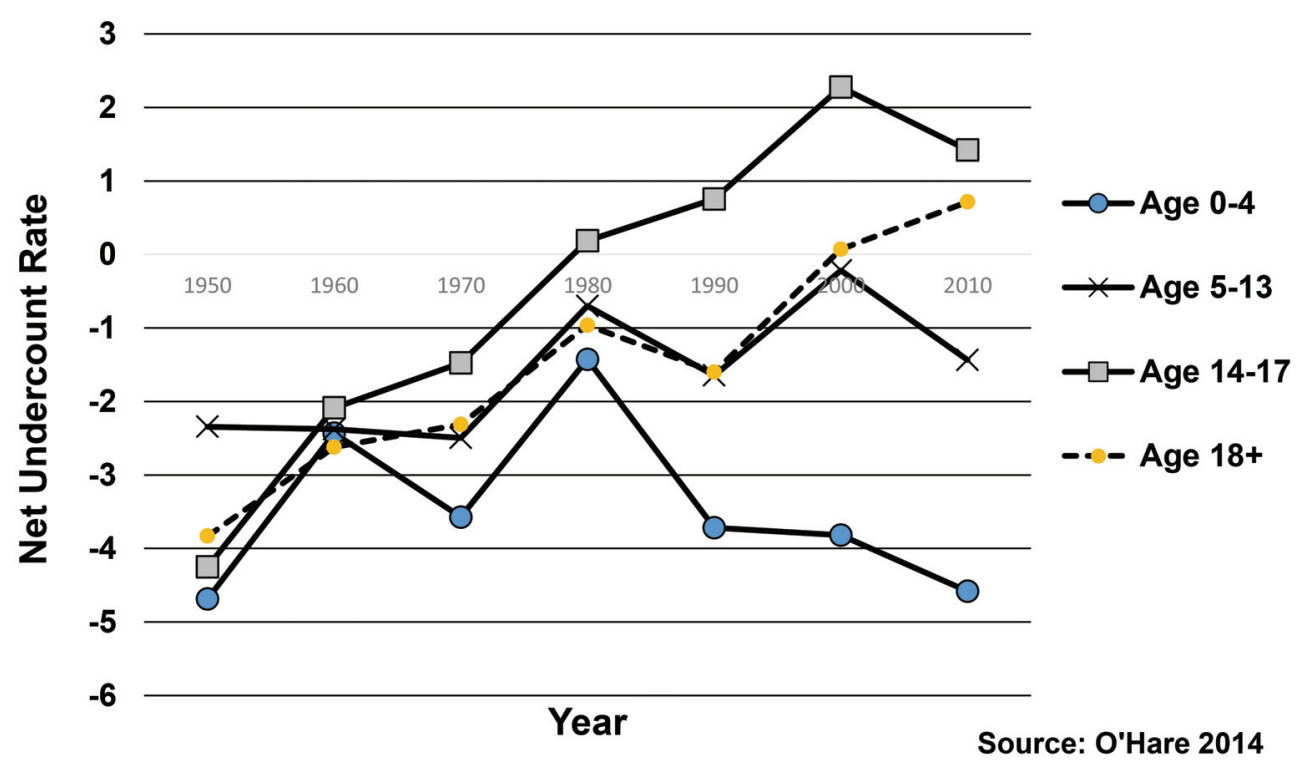

Fig. 4. Net undercount rates for different ages groups of children in the U.S. Census: 1950 to 2010.

net Census coverage rates in the 2010 U.S. Decennial Census. In addition, these age groups have some social significance because they roughly correspond to the preschool-age population, the elementary and middle school-age population, and the high school-age population.

Figure 4 shows that there has been growing divergence in Census coverage rates for children of different ages and that the differences among age groups are more striking after 1980 than before.

Perhaps the most striking aspect of Fig. 4 is the change in the net undercount rates of young children following the 1980 U.S. Census. Between 1980 and 2010 , the net undercount rate for young children increased from 1.4 percent to 4.6 percent. Recall that over the same period the net undercount rate of adults continued the improvement that had been witnessed during the 1950 to 1980 period. What happened after 1980 that altered the trajectory of net undercount rates for young children? The profession has not offered any answers to this question. Similar to the adult population, the net undercount rates for the population age 14 to 17 has shown a steady decline since 1980 .

The net undercount rate for young children in 2010 (4.6 percent) is almost the same as the rate experienced by this age group in the 1950 U.S. Census (4.7 percent). Over the same time period the net undercount rate for the population age 14 to 17 fell from 2.3 percent to a net overcount of 1.5 percent; a 3.8 percentage point swing. This underscores the importance of examining children by age not only in terms of current results but in historic trends as well.

Another perspective on the data in Fig. 4 is expressed by Hogan (2013). If one ignores the results from the 1980 U.S. Census, there has been relatively little movement in the net undercount of young children between 1950 and 2010. If one discounts the 1980 results, the net undercount of young children was between -2.4 percent and -4.6 percent in every U.S. Census from 1950 to 2010 without much of a temporal pattern before or after 1980. The results for 1980 may be different from the other U.S. Censuses because there was a major effort to reduce the undercount in 1980 , in part, because of political pressure for an adjustment of Census figures in the face of persistent undercount differentials [4, Chapter 3].

From this perspective the question is not what happened after 1980, but rather why has there been consistently high net undercount rates for young children since 1950 while the net undercount rate for adults steadily improved? The profession has not offered any answers to this question.

The data examined here show three key patterns with respect to the net undercount of young children in the U.S. Census.

1) Young children routinely have a high net undercount

2) Young children have a higher net undercount than older children

3) Young children have a higher net undercount than any other age group (since 1970) 
The next section of the study examines censuses from other countries in light of the key findings noted above.

\section{Counting young children in the Census: An international comparative perspective}

The analysis here is framed by comparing the results in other countries to the key results in the U.S. Three specific questions are addressed related to patterns seen in the U.S. Census:

1. Is a net undercount rate (as opposed to a net overcount) for children under age 5 common?

2. Is the net undercount rate for children under age 5 commonly higher than the net undercount rate for older children?

3 . Is the net undercount rate for children under age 5 commonly higher than the net undercount rate for any other age group?

The Censuses examined here were conducted under a variety of conditions and use several different methods to evaluate results, but it is not my intention to examine the results from a methodological perspective. There are several good descriptions of international approaches to measuring Census coverage $[10,17,23]$. The point here is to see if the patterns found in a variety of other countries are consistent with the results of the U.S. Census.

The comparisons here are driven largely by the data available from the respective countries. Many countries do not conduct systematic assessments of their Censuses and/or they do not make them publically, or at least easily available. In addition, I was limited to studies reported in English. Most reports on Census undercounts provide only limited detail with respect to net undercount by age. Some coverage reports were not relevant for this study because they do not show data for young children. In addition components of net coverage (omissions and erroneous inclusions) are seldom reported so the analysis here focuses on net coverage errors.

The collection of countries examined here is certainly not a representative sample, but the sizable number of countries included here and the fact that they reflect different methods for census-taking and for evaluation make the findings more robust. In addition, they represent many different levels of socioeconomic development, different cultures, and different censustaking traditions.
Only a few previous studies have compared multiple countries in terms of Census coverage. For example, Simpson and Middleton [43] examined the results of Censuses from Australia, Britain, Canada and the United States to find characteristics of non-response that are common among those countries. The results from Simpson and Middleton list six characteristics associated with high non-response rates across the countries;

- Single and divorced males

- Recent migrants

- Unemployed

- Minority ethnic groups

- Private renters

- Those who share a dwelling with other households or with a business

Interestingly, none of these characteristics reflect children or characteristics closely related to children.

I found only one study containing international comparisons related to the coverage of children in multiple Censuses. After assessing the coverage of children in the 2000 Chinese Census, Anderson [5] examined selected Census results for children from Australia, New Zealand, South Africa, Soviet Union and the United States and generally finds net undercounts of young children in all of the countries examined. The paper by Anderson provides several tables with Census coverage data on young children as well as other age groups but the text section of the paper devotes only three paragraphs to young children. Some of the results shown in Andersons' study are repeated and updated here.

\subsection{Is a net undercount rate (as opposed to a net overcount) for children under age 5 common?}

Table 3 provides data on net undercount rates for children in the six countries. For every country except New Zealand, data are reported for age 0 to 4 . New Zealand reports age 0 to 14 . In a few cases data were only reported by sex, not for the total population, so I use the undercount estimates for males and females separately.

In every one of the 22 examples in Table 3 there was a net undercount of children age 0 to 4 . But the rate varied over time and across countries. The minimum value seen was a 1.2 percent net undercount rate, and the maximum value was a 15.1 percent undercount rate.

The mean for all 22 rates for the population age 0 to 4 in Table 3 is -4.3 percent, but it should be noted 
Table 3

Net census undercount rates for children and other age groups from selected countries and selected years

\begin{tabular}{|c|c|c|c|c|}
\hline New Zealand Age & $0-14$ & & & Age 15-29 \\
\hline 1996 & -1.7 & & & -2.5 \\
\hline 2001 & -2.7 & & & -3.1 \\
\hline 2006 & -1.0 & & & -4.1 \\
\hline South Africa & Age $0-4$ & Age 5-9 & Age $10-14$ & Age $20-29$ \\
\hline 2011 & -15.1 & -11.4 & -11.1 & -18.1 \\
\hline Canada & Age $0-4$ & Age 5-14 & Age $15-17$ & Age $20-24$ \\
\hline 1976 & -2.3 & -1.2 & -2.0 & -5.3 \\
\hline 1981 & -1.2 & -1.2 & -3.0 & -5.5 \\
\hline 1986 & -2.1 & -2.1 & -3.6 & -8.7 \\
\hline 1991 & -3.6 & -2.5 & -3.8 & -8.2 \\
\hline 1996 & -2.9 & -1.5 & -3.5 & -8 \\
\hline 2001 & -4.4 & -2.9 & -4.4 & -9.9 \\
\hline 2006 & -4.1 & -3.1 & -4.4 & -10.5 \\
\hline 2011 & -3.4 & -2.7 & -2.7 & -9.6 \\
\hline Australia & Age $0-4$ & Age 5-9 & Age $10-14$ & Age $20-24$ \\
\hline 1976 Males & -2.9 & -2 & -1.8 & -5.6 \\
\hline 1976 Females & -3.1 & -1.7 & -1.5 & -3.9 \\
\hline 1991 & -1.6 & -1.4 & -1.1 & -3.6 \\
\hline 1996 & -1.4 & -1.4 & -1.0 & -3.5 \\
\hline 2001 & -1.5 & -1.5 & -1.2 & -3.1 \\
\hline 2006 & -3.4 & -2.4 & -2.1 & -6.8 \\
\hline 2011 & -1.2 & -1.5 & -0.4 & -6.9 \\
\hline England and Wales & Age $0-4$ & Age 5-9 & Age $10-14$ & Age $20-24$ \\
\hline 1991 Males & -5.5 & -4.0 & -3.5 & -11.0 \\
\hline 1991 Females & -5.0 & -2.5 & -2.0 & -5.0 \\
\hline 2001 Males & -9.0 & -7.0 & -7.0 & -13.0 \\
\hline 2001 Females & -9.0 & -7.0 & -7.0 & -11.0 \\
\hline 2011 & -9.6 & -8.0 & -6.6 & -10.9 \\
\hline France Age $0-4$ & Age 5-9 & Age $10-14$ & Age 20-24 & \\
\hline 2006 & -1.9 & 1.8 & 1.9 & -0.6 \\
\hline
\end{tabular}

"For consistency, net undercounts are denoted with a negative sign". Sources: see note at the end of text.

that this mean includes South Africa where the net undercount rate for young children was -15.1 percent. This mean also includes several cases where male and female rates are included separately. In the three cases for New Zealand where only data for age 0 to 14 are available, all three cases show a net undercount for children.

Table 4 provides data from an article by Goodkind [18] containing net undercount rates of young children from eleven Asian countries. In 10 of the 11 countries in Table 4 there was a net undercount of children age 0 to 4 . The Census coverage rates for age 0 to 4 range from a 15.9 percent net undercount in Mongolia to a 0.3 percent net overcount in Taiwan. The mean for the 11 net undercount rates for age 0 to 4 shown in Table 4 is -7.4 percent Seven of the eleven countries had net undercount rates for age 0 to 4 of five percent or higher.

Table 5 provides nine estimates for undercounts of children age 0 to 4 in various Chinese Censuses from a couple of different sources. In every case, there was
Table 4

Census coverage rates for young children in selected asian countries

\begin{tabular}{lccc}
\hline & Date & $\begin{array}{c}\text { Coverage rate } \\
\text { for age 0-4* }\end{array}$ & $\begin{array}{c}\text { Coverage rate } \\
\text { for age 5-9* }\end{array}$ \\
\hline Mongolia & 2000 & -15.9 & -7.1 \\
Indonesia & 2000 & -13.4 & -7 \\
Cambodia & 1998 & -11.4 & -3.9 \\
Vietnam & 1999 & -10.1 & -0.1 \\
Philippines & 1995 & -7.90 & -3.6 \\
Sri Lanka & 2001 & -7.60 & -5.3 \\
Thailand & 2000 & -5.30 & -2.1 \\
Macau & 2001 & -3.90 & 1.1 \\
South Korea & 2000 & -3.60 & -3.3 \\
Japan & 2000 & -2.30 & -1.2 \\
Taiwan & 2000 & 0.30 & -0.3 \\
Mean & & -7.40 & -3.0 \\
\hline
\end{tabular}

* Negative numbers indicate an implied undercount and positive numbers indicate an implied overcount. Source: Authors reconfiguration of data in an article by Goodkind (2011).

a net undercount for children age 0 to 4 and in some cases the estimated net undercounts were very high.

The evidence presented here indicates that a net undercount of young children is common in many coun- 
Table 5

Estimated net census undercounts of children in china

\begin{tabular}{llc}
\hline Date & $\begin{array}{c}\text { Coverage rate for } \\
\text { age } 0 \text { to } 4\end{array}$ & $\begin{array}{c}\text { Coverage rate for } \\
\text { age } 5 \text { to } 9\end{array}$ \\
\hline 1982 & -4.2 & 0.4 \\
1982 & -7 & 0.8 \\
1990 & -4.8 & -2.1 \\
1990 & -8 & -4.2 \\
2000 & -26.2 & -12.1 \\
2000 & -17.2 & -4.4 \\
2000 & -19.1 & -11.9 \\
1990 & & \\
Male & 6.2 & \\
Female & 7.5 & \\
\hline
\end{tabular}

Sources: Goodkind (2011): Cai and Lavely (2003).

tries around the world. For the all of the examples examined in Tables 3, 4, and 5 (including age 0 to 14 in New Zealand) there is only one instance (Taiwan in 2000) where there was a net overcount of young children, and that net overcount was very small.

There is another pattern evident in Tables 3 and 4. For the more developed countries shown in Table 3, the gap between the net undercount rate of those age 0 to 4 and the net undercount of those age 5 to 9 , is smaller than the gap in the first 8 Asian countries shown in Table 4 which are less developed countries. However, the three Asian countries at the bottom of Table 4 (Japan, South Korea and Taiwan) the gap between the undercount rates of age 0 to 4 and those of age 5 to 9 , are more like those seen in the more developed countries in Table 3. Japan, South Korea and Taiwan which are among the more economically developed countries in Asia.

In addition to the systematic data shown in Tables 3, 4 , and 5 there are a few other examples in the literature of Census evaluations which show net undercounts of young children. Recent evaluation of the Philippine Censuses in 2000 and 2010 found a net undercount of young children [12]. Depending on the method used the net undercount for the population age 0 to 4 was in the range of 5 to 10 percent. By comparing Census results to school enrollment, Anderson and Silver [2] concluded that there was an under-enumeration of children and adolescents in the 1959 and 1970 Soviet Censuses. Similar results were reported by Baldwin [7]. Desplanques [15] reviews data from 1990 to 2007 comparing Census results and vital records for people born in metropolitan areas of France. In general his data show that younger children typically have a net undercount rate between 2 and 6 percent. In reviewing the 2001 South African Census figures for a selected rural geographic area within country, Nyirenda et al. (no date, page 1) conclude, "Despite the almost uni- versal participation rates of the studied population in the longitudinal demographic surveillance, we still find evidence of under enumeration of children."

In many instances, infants face high odds of being undercounted. For example the 1976 New Zealand Census, Yurjevich [62] estimated that 3 percent of those less than one year of age were missed. Two somewhat dated reports from the U.S. Census Bureau $[44,45]$ also indicate a high net undercount of infants in the past.

The pattern seen in Censuses from a wide variety of countries is similar to the pattern seen in the U.S. In almost every case examined here, the population age 0 to 4 had a net Census undercount.

\subsection{Is the net undercount rate for children under age 5 commonly higher than the net undercount rate for older children?}

Data in Table 3 show that in most cases the net undercount rate for those age 0 to 4 is higher than that for older children. In Table 3 there are 14 instances where net undercount rates are available for age 0 to 4 and age 5 to 9 . In every instance except one (Australia in 2011) the net undercount rate for age 0 to 4 is as high or higher than that of age 5 to 9. In 1996 and 2001, the rates for age 0 to 4 and 5 to 9 in Australian are the identical. The mean undercount rate for age 0 to 4 for the 14 rates shown in Table 3 is -5.0 percent compared to -3.6 percent for age 5 to 9 .

The Canadian data shown in Table 3 indicates that the net undercount of children under age 5 are as high or higher that the net undercount rate for children age 5 to 14 , but typically not as high as the net undercount rate for children age 15 to 17 .

In Table 4 there are 11 sets of net undercount rates for age 0 to 4 and 5 to 9 in 11 Asian countries. In every one of the countries, except Taiwan, the net undercount for children age 0 to 4 was higher than the net undercount for children age 5 to 9 . For data presented in Table 4 the mean net undercount rate for age 0 to 4 was -7.4 percent and for age 5 to 9 it was -3.0 percent.

The data for China shown in Table 5 provide seven examples with net undercount data for age 0 to 4 and age 5 to 9 . In every case, the net undercount for age 0 to 4 is higher than the net undercount rate for age 5 to 9.

The data in Table 3 also allow for 14 direct comparisons of the net undercount of children age 0 to 4 with the undercount rates of children age 10 to 14 . In every comparison examined the net undercount rate of young 
children is higher than that of children age 10 to 14 . For the 14 rates in Table 3 the mean undercount rate for age 0 to 4 was -5.0 percent compared to -3.2 percent for age 10 to 14 .

The findings above are consistent with the observations of others. For example, after reviewing data from several different Censuses, Anderson [5, page 10] concludes "Young children are less reliably captured than children in their early teens, for both sexes." Desplanques [15], Fig. 2 reviews data from 1990 to 2007 comparing Census results and vital records for people born in metropolitan areas of France. In general his analysis shows that younger children typically had slightly higher net undercount rates than older children. After reviewing census results from several countries, Simpson and Middleton [43, page 4] conclude, "The following features are apparent. Young children are less reliably captured than children in their early teens for both sexes."

The pattern seen in Censuses from a wide variety of countries is similar to the pattern seen in the U.S. In almost every case examined here, the population age 0 to 4 had a higher net Census undercount than older children.

\subsection{Is the net undercount rate for children under age 5 higher than the net undercount rate for any other age group?}

The net undercount rate for young children the 2010 U.S. Census is twice as high as any other age group. In that regard the United States is an outlier. Based on a subset of the countries examined in the previous two sections, young children typically do not have the highest net undercount rate of any age group. In most countries examined here young adults have a higher net undercount rate than young children.

Table 3 shows net undercount rates for young children and for young adults in different countries. The exact age of young adults varies by country. For all of the countries except New Zealand and South Africa data are shown for young adults age 20 to 24 .

There were 21 cases where net undercount rates for children age 0 to 4 could be compared with net undercount rates for the population age 20 to 24 . In almost every case where data are available for both age groups, (age 0 to 4 and a group somewhere in the 15 to 30 age range) the net undercount of young adults (people age 20 to 24) is higher than that of age 0 to 4. For the 21 cases where data were available for both age $0-4$ and $20-24$, the mean net undercount rate for age $0-4$ was 3.8 percent compared to 7.2 percent for age 20-24. In New Zealand the comparison is between people age 0 to 14 and people age 15 to 29 . In every case those age 15 to 29 have a higher net undercount rate than those age 0 to 14 .

The data above is consistent with many observations about Census-taking. In a comparative review of Censuses from several countries, Anderson [5, page 10] concludes "Young adult men were hardest to enumerate." A report on the 2001 Australia Census by the Australian Bureau of Statistics [6, page 20] concludes, "The likelihood of enumerating a person in the Census is closely linked to the age and sex of that person. As has been observed in previous Censuses in Australia, as well as in Censuses overseas, young adult males are the group least likely to be enumerated in the Census." In preparing for the 2011 Census in Great Britain, the population of adults age 20 to 29 was categorized as having a high likelihood of being Hard-To-Count, while they note the 2001 Census nonresponse rate for this group was 11.9 percent [1]. Simpson and Middleton [43] conclude that, "Young adult men are the hardest group to enumerate."

The evidence suggests that the U.S. is an outlier in terms of young children having the highest net undercount rate of any age group. For most countries examined here, young adults have the highest net undercount rate.

\section{Discussion}

The data examined in this study indicate that like the United States, young children are undercounted in many other censuses around the world. Moreover, young children tend to have higher net undercounts that older children in nearly every census examined here.

The countries examined here are a haphazard sample of all countries but the strong patterns seen here suggest that a high net undercount of young children in censuses is a common problem around the world.

Despite the evidence of high net undercounts for young children there is a dearth of studies focused on this issue and no literature I could find focused on why young children have such a high net undercount. There are a couple of recent publications $[19,28,34]$ that begin to tease out possible explanations for the high net undercount of young children in the U.S. Census, but I could not find any study that examined reasons for the high net undercount of young children across coun- 
tries. The widespread nature of this problem, suggests that countries may profit from working together to address this issue.

There a couple of possible reasons why the high net undercount of young children has not received more attention. One reason may be that the high net undercount of young children is counterintuitive to many people. People are surprised to learn that young children have a higher net undercount rate than any other age group. In the words of former U.S. Census Bureau Director Robert Groves [55],

"It's often a surprise to many people when they learn that children tend to be undercounted in the US Censuses. Most can imagine various types of adults who fail to participate in Censuses, but don't immediately think of children being missed."

Daponte and Wolfson [14, page 2] also acknowledge the lack of recognition of Census undercounts of young children and state, "What is not well-recognized is that children tend to be undercounted at a rate greater than that of the general population."

A second reason this issue has not be pursued is because it is inconsistent with much of the survey methodology literature which shows households with children are generally more likely to respond to a survey than households without children [56]. Groves and Couper [56, page 138] offer this succinct summary of the relationship between children in the household and cooperation in survey research, "Without exception, every study that has examined response or cooperation finds positive effects of the presence of children in the household." However, it should be noted that there is no distinction made in Groves and Couper's review of the literature about the age of the children in the household. It should also be noted that a household response does not mean every person in the household is included in the response. A household could respond to the Census, for example, but fail to include a young child on the returned Census questionnaire.

The issue of census coverage of young children is also intertwined with both evolving methods for conducting censuses and methods for evaluating those counts. Many countries already use administrative records in their census-taking procedures and the U.S. is planning to do so in the 2020 U.S. Decennial Census. However, this raises another issue. In the U.S. young children are under-represented in the administrative records the Census Bureau is planning to use. O'Hare [34] shows that only 81 percent of those age 0 to 2 included in the 2010 U.S. Decennial Census were also included in administrative records compared to over 90 percent of adults. This suggest that we must be very careful about how administrative records are used in the context of the U.S. Decennial Census.

\section{Summary}

There is strong evidence of a high net undercount of young children in the U.S. Census. Like the U.S. experience, net Census undercounts are seen for young children in almost every country examined here. Generally young children have higher net undercount rates that older children in the Censuses examined here.

Unlike the U.S. experience, in most of the Censuses examined here young children are not the age group with the highest net undercount rates. The highest rates are typically for young adults, especially young adult males.

Given the relatively pervasive patterns seen among the countries studied here, the topic of net undercount of young children merits further study in additional countries. The strong patterns observed in this collection of countries suggest the findings shown here are likely to be found elsewhere as well. In addition to documenting census coverage of young children, it is important for the field to begin addressing the question of why young children experience high net undercounts.

\section{Acknowledgments}

The author would like to thank two anonymous reviewers for their very helpful comments on an earlier version of this manuscript.

\section{References}

[1] O. Abbott and G. Compton, Counting and estimating hardto-survey populations, in: Hard-to-Survey Populations, R. Tourangeau, B. Edwards, T.P. Johnson, K.M. Wolter and N. Bates, eds, Cambridge University Press, Cambridge, England, 2015, pp. 58-81.

[2] B.A. Anderson and B.D. Silver, Estimating Census Undercount from School Enrollment Data: An Application to the Soviet Censuses on 1959 and 1970, Demography 22(2) (May 1985), 289-308.

[3] M.J. Anderson, C.F. Citro and J.J. Salvo, eds, Encyclopedia of the U.S. Census: From the Constitution to the American Community Survey (ACS), Sage Publications, 2012.

[4] M.J. Anderson and S.E. Fienberg, Who Counts? The Politics of Census-Taking in Contemporary America, Russell Sage Foundation, New York, 1999. 
[5] B.A. Anderson, Undercount in China's 2000 Census in Comparative Perspective, PSC Research Report, No. 04-565, Population Studies Center, University of Michigan, Ann Arbor, MI, 2004.

[6] Australian Bureau of Statistics (2003). Information Paper: Census of Population and Housing Data Quality- Undercount, 2940.0, Dennis Trewin, Canberra.

[7] G. Baldwin, Estimates and Projections of the population of the U.S.S.R. by age and sex: 1950-2000, U.S. Department of Commerce, International Population Reports, Series P-91, No. 24. Washington DC, 1973.

[8] R. Bhaskar, M. Scopilliti, F. Hollman and D. Armstrong, Plans for Producing Estimates of Net International Migration for the 2010 Demographic Analysis Estimates, Census Bureau Working Paper No. 90, 2010.

[9] T. Bryan, "Population Estimates," in: The Methods and Materials of Demography, J. Siegel and D. Swanson, eds, Elsevier Academic Press, 2004, 523-560.

[10] T. Bryan and R. 'Heuser, "Collection and Processing of Demographic Data," in: The Methods and Materials of Demography, J.S. Siegel and D.A. Swanson, eds, Elsevier Academic Press, 2004, pp. 43-64.

[11] Y. Cai and W. Lavely, China's Missing Girls: Numerical Estimates and Effects on Population Growth, The China Review 3(2) (Fall. 2003).

[12] G.C. Cruz, J.P. Cruz and M.M. Kabamalan, Assessing and Adjusting the 2000 Philippine Census Population Count, Poster Presented at the Population Association of America Conference, Boston, MA. May 1-3, 2014.

[13] Demographic Analysis Research Team (2010). "Estimates of Net International Migration in Demographic Analysis," Population Division, U.S. Census Bureau, presentation at 2010 Demographic Analysis Conference, Washington DC, December 6.

[14] B.O. Daponte and L.J. Wolfson, How many American Children are Poor? Considering Census Undercounts by Comparing Census to Administrative Data, unpublished paper, 2003s.

[15] G. Desplanques, Strengths and Uncertainties of the French Annual Census Surveys, Population-E, 2008, pages 415-440.

[16] J. Devine, L. Sink, B. DeSalvo and R. Cortes, "The Use of Vital Statistics in the 2010 Demographic Analysis Estimates," Census Bureau Working Paper No. 88, 2010.

[17] M. Elkin, P. Dent and N. Rahman, A Review of international approaches to estimating and adjusting for under-and overcoverage, Office of National Statistics, United Kingdom, London, 2012.

[18] D. Goodkind, Child Underreporting, Fertility and Sex Ratio Imbalance in China, Demography 48 (2011), 291-316.

[19] D.H. Griffin, Final Task Force Report: Task Force on the Undercount of Young Children, Memorandum for Frank A. Vitrano, U.S. Census Bureau, Washington, DC. February 2, 2014.

[20] C.L. Himes and C.C. Clogg, An Overview of Demographic Analysis as a Method For Evaluating Census Coverage in the United States, Population Index 58(4) (1992), 587-607.

[21] H. Hogan, Presentation at the 2013 Joint Statistical Meetings, Montreal Canada, 2013

[22] H. Hogan, P. Cantwell, J. Devine, V.T. Mule and V. Velkoff, Quality and the 2010 Census, Population Research and Public Policy 32 (2013), 637-662.

[23] D. Kerr, A Review of procedures for estimating the net undercount of Censuses in Canada, the United States, Britain, and Australia, Statistics Canada, Ottawa, Canada, 1998.

[24] M. Mulry, Measuring Undercounts for Hard-to-Reach
Groups, in: Hard-to-survey Populations, R. Tourangeau, B. Edwards, T.P. Johnson, K.M. Wolter and N. Bates, eds, Cambridge University Press, 2014.

[25] National Center for Health Statistics (2014). Assessing the Quality of Medical and Health Data from the 2003 Birth Certificate Revision: Results from Two States, National Vital Statistics Reports, Volume 62, No. 2. U.S. Department of Health and Human Services, Centers for Disease Control and Prevention.

[26] M. Nyirenda, V. Hosehood and T.A. Moultrie, (no date). Population modelling for a small area: a comparative analysis of Census and demographic surveillance system data in South Africa, African Centre for Health and Population Studies, KwaZulu Natal, South Africa.

[27] W.P. O'Hare, J.G. Robinson, K. West and T. Mule, Comparing Demographic Analysis and Dual-Systems Estimates Results for Children, Paper presented at the Southern Demographic Association Conference, Williamsburg VA, 11-12 October 2012.

[28] W.P. O'Hare, Potential Explanations for the High Net Undercount of Young Children in the U.S. Census, Paper presented at the 2014 Applied Demography Conference at the University of Texas, San Antonio, TX, (2014, January).

[29] W.P. O'Hare, Assessing Net Coverage Error for Young Children in the 2010 U.S. Decennial Census, Center for Survey Measurement Study Series (Survey Methodology \#2014-02). U.S. Census Bureau, 2014.

[30] W.P. O'Hare, Historical Examination of Net Coverage Error for Children in the U.S. Decennial Census: 1950 to 2010, Center for Survey Measurement Study Series (Survey Methodology \#2014-03). U.S. Census Bureau, Washington, DC, 2014.

[31] W.P. O'Hare, Estimating the Net Undercount of Young Children in the 2010 U.S. Decennial Census at the County Level, Poster presented at the 2014 Population Association of America Conference, Boston, MA, 2014, April.

[32] W.P. O'Hare, State-Level 2010 Census Coverage Rates for Young Children, Population Research and Policy Review 33(6) (2014), 797-816.

[33] W.P. O'Hare, Assessing Net Coverage for Young Children in the 2010 U.S. Decennial Census, International Journal of Population Research 2014.

[34] W.P. O'Hare, The Undercount of Young Children in the U.S. Decennial Census, Springer Publishers, 2015.

[35] W.P. O'Hare, What Do We know About the Presence of Young Children in Administrative Records, Federal Conference on Statistical Methodology, Washington, DC. December, 2015 .

[36] J. Pitkin and J. Park, The Gap Between Births and Census Counts of Children Born in California: Undercount or Transnational Movement? Paper presented at the Population Association of America Conference, Philadelphia PA. March, 2005 .

[37] J.G. Robinson, Accuracy and Coverage Evaluation: Demographic Analysis Results, U.S. Census Bureau, DSSD Census 2000 procedures for operations Memorandum Series B-4, U.S. Census Bureau, 2000, Page 1.

[38] J.G. Robinson, Coverage of Population in Census 2000 Based on Demographic Analysis: The History Behind the Numbers, U.S. Census Bureau, Working Paper No. 91, 2010.

[39] J. Schachter, Estimating Native Emigration from the United States, Memorandum date December 24, delivered to the U.S. Census Bureau, 2008.

[40] R. Shores and R. Sands, Correlation Bias Estimation in the Accuracy and Coverage Evaluation Revision II, Proceedings 
of the Survey Research methods Section, Joint Statistical Meetings, 2003.

[41] R. Shores, Accuracy and Coverage Evaluation Revision II Adjustment for Correlation Bias, DSSD, A.C.E. REVISION II MEMORANDUM SERIES PP-53, U.S. Bureau of the Census, Dec 2002.

[42] J.S. Siegel and M. Zelnik, An Evaluation of Coverage in the 1960 U.S. Census of Population by Techniques of Demographic Analysis and by Composite Methods, in: Proceedings of the Social Statistics Section of the American Statistical Association: Washington, D.C.: American Statistical Association, 1966, 71-85

[43] L. Simpson and E. Middleton, Who is missed by a National Census? A review of empirical results from Australia, Britain, Canada, and the USA, The Cathie Marsh Centre for Census and Survey Research, University of Manchester UK, 1997.

[44] U.S. Census Bureau, Population Differential Fertility: 1940 and 1910; Standardized Fertility Rates and Reproduction Rates, Appendix A, Completeness of Enumeration of Children Under 5 Years Old in the U.S. Census of 1940 and 1910 , 1940 Census, U.S. Census Bureau, Washington, DC, 1944.

[45] U.S. Census Bureau, Infant Enumeration Study, 1950 Procedural studies of the 1950 Censuses, No. 1, Washington, DC, 1953.

[46] U.S. Census Bureau, Technical Assessment of A.C.E. Revision II, U.S. Census Bureau, Washington, DC, 2003.

[47] U.S. Census Bureau, Residence Rules and Residence Situation for the 2010 Census, available at, http://www.census.gov/ population/www/cen2010/resid_rules/resid_rules. html down loaded February 6, 2016.

[48] U.S. Census Bureau, Tables released at December 2010 Conference, 2010

[49] U.S. Census Bureau, Documentation for the Revised 2010 Demographic Analysis Middle Series Estimates, 2012.

[50] U.S. Bureau of the Census, U.S. Population Projections: 2014-2060, Release Number CB14-TPS.86, U.S. Census Bureau, Washington, DC. U.S. Census Bureau (2003), Technical Assessment of A.C.E. Revision II, U.S. Census Bureau, Washington, DC, 2014.

[51] U.S. Census Bureau, The Development and Sensitivity Analysis of the 2010 Demographic Analysis Estimates, Population Division Background paper of DA Conference Dec 6, 2010. 11/29/2010, Table 2, U.S. Census Bureau, Washington, DC, 2010 .

[52] U.S. Census Bureau, Tables released at December 2010 Conference, 2010

[53] U.S. Census Bureau, Documentation for the Revised 2010 Demographic Analysis Middle Series Estimates, U.S. Census Bureau, Washington, DC, 2012.

[54] U.S. Census Bureau, DSSD 2010 Census Coverage Measurement Memorandum Series \#2010-G-11, 2010 Census Coverage Measurement Estimation Reports: Adjustment for Correlation Bias, U.S. Bureau of the Census, Washington, DC, 2012.

[55] R. Groves, Children Count Too! Census BureauâĂŹs Directors Blog March 9, U.S. Census Bureau, Washington, DC, 2010.

[56] R.M. Groves and M.P. Couper, Nonresponse in Household Interview Surveys, John Wiley and Sons, 1998.

[57] U.S. Office of Management and Budget, Revisions to the Standards for the Classification of Federal Data on Race and Ethnicity, Statistical Policy Directive 15, Federal Register Notice, October 30, 1997.

[58] J. Van Hook, F.D. Bean, J.D. Bachmeier and C. Tucker,
Recent Trends in Coverage of Mexican-Born Population of the United States, Results from Applying Multiple Methods Across Time, Demography, published on line 26, February 2014, DOI 10.1007/s13524-014-0280-2, 2014.

[59] V. Velkoff, Demographic Evaluation of the 2010 Census, Paper presented at the 2011 PAA annual Conference, Washington, DC, March, 2011.

[60] K.K. West, J.G. Robinson and M. Bentley, Did Proxy Respondents Cause Age Heaping in the Census 2000? Paper delivered at the Joint Statistical Meetings, ASA Section on Survey Research Methods, 2005.

[61] K. West, J. Devine and J.G. Robinson, An Assessment of Historical Demographic Analysis Estimates For the Black Male Birth Cohorts of 1935-39, Paper presented at the Annual Meeting of the American Statistical Association, Boston MA, 2014.

[62] M. Yurjevich, "Underenumeration of babies in the 1976 Census of Population and Dwellings," Demographic Bulletin, 4(2), Department of Statistics, Wellington, 1982.

Sources for the data shown in Table 3 are listed below

Dolson, D., (2013). Differential Coverage Error for Young Children in the Canadian Census, presentation at the Joint Statistical Meeting, Montreal, Canada August. (Authors calculation from Chart in Dolson presentation).

Statistics Canada (2004). 2001 Census Technical Report: Coverage, Statistics Canada Catalogue no. 92-394-X, Ottawa, Canada.

Statistics Canada (2010). 20011Census Technical Report: Coverage, Statistics Canada Catalogue no. 92-567-X, Ottawa, Canada.

Table 11.2 page 102 .

New Zealand

Statistics New Zealand (2007). A Report on the 2006 Postenumeration Survey, Table 1, Wellington, NZ. Table 1, page 11.

Anderson, B. A. (2004). Undercount in China's 2000 Census in Comparative Perspective, PSC Research Report, No. 04-565, Population Studies Center, University of Michigan, Ann Arbor, MI. Figure 11 , page 9 .

South Africa

Statistics South Africa, Office of Population Censuses and Surveys, (1993).

Statistics South Africa (2012). Post-enumeration Survey: Results and methodology, Report No. 03-01-46, Pretoria, South Africa. Table 11 .

England

Office of National Statistics (2012) Response Rates in the 2011 Census, London.

Office of National Statistics (2005) Census 2001; Quality Report for England and Wales, London, England.

France

Desplanques, G., (2008). "Strengths and Uncertainties of the French Annual Census Surveys," Population-E, pages 415-440. Australia

Anderson, B. A. (2004). Undercount in China's 2000 Census in Comparative Perspective, PSC Research Report, No. 04-565, Population Studies Center, University of Michigan, Ann Arbor, MI. Figure 9 page 8 .

Australian Bureau of Statistics (1991). Census of Population and Housing, Census 91: Data Quality Undercount Report no. 2940.0, Canberra.

Australian Bureau of Statistics (1995). Census of Population and Housing, 6 August 1991 Census 91; Data Quality - Undercount, Canberra, Australia.

Australia Bureau of Statistics (1997). Census of Population and 
Housing: Data Quality - Undercount; 1996, Canberra, Australia. Australian Bureau of Statistics (1999). Demography Working Paper 1999/4 - Measuring Census Undercount in Australia and New Zealand, Report 3118.0, Canberra.

Australian Bureau of Statistics (2003). Information Paper: Census of Population and Housing Data Quality-Undercount, 2940.0, Dennis Trewin, Canberra.

Australian Bureau of Statistics (2007). Census of Population and Housing - Undercount 2006, paper 2940.0, Canberra, Australia.
Australian Bureau of Statistics (2012). Census of Population and Housing - Details of Undercount, 2011 report 2940.0, Canberra.

Australian Bureau of Statistics (2012). Census of Population and Housing - Details of Undercount, 2011, 2940.0, Canberra, Australia. Australian Bureau of Statistics (2012). Information Paper, Measuring Net Undercount in the 2011 Population Census, Report no. 2940.55.001, Canberra. 